\title{
Ann Based Fault Protection Scheme for Power Transformer
}

\author{
M. Priyadharshini ${ }^{1}$, K. Gayathri ${ }^{2}$, C. Poongothai ${ }^{3}$ \\ Assistant Professor, Dept. of Electrical Engg, Annamalai University, Annamalai Nagar, India ${ }^{1,2}$ \\ M.E, Power System Student, Dept. of Electrical Engg, Annamalai University, Annamalai Nagar, India ${ }^{3}$
}

\begin{abstract}
This paper introduced fault diagnosis system for power transformer using an Artificial Neural Network (ANN). This system is to identify, localize and classify the faults. This system consists of various stages. In first stage, a preprocessing procedure for input data is performed. In second stage an ANN is designed to identify fault and to localize its side. In third stage, there are two sub diagnosis systems. Each system has one ANN designed to classify the fault. The performance of fault diagnosis system is evaluated using samples from local measurements (three-phase primary voltage and primary\& secondary currents). The faults that are detected and cleared are single winding, double winding, and inrush currents.
\end{abstract}

Keywords: ANN, Power Transformer, Fault Protection.

\section{INTRODUCTION}

One of the most important and complex systems that has been built by human civilization is the power system. One of the most important components of any power system is the power transformer. Transformer is the most essential element in power system. The protection of Transformers is critical phenomenon. Traditionally, transformer protection methods that use its terminal behaviours are based on differential protection is considered as a most widely used technique to perform the protection function. The differential protection scheme can be used to protect both the primary and secondary windings of a three-phase transformer against faults. The method fundamentally based on the discrimination between faults and other operating conditions [1]. The commonly used conventional differential protection based on second harmonic restraint will face difficulties in distinguishing the input current and internal faults. Therefore, an improved technique for protecting discriminate between the input current and internal faults are required [2]. In this paper power transformer faults (single, double, inrush) are detected and cleared using ANN.

\section{METHODOLOGY FOR TRANSFORMER FAULT PROTECTION USING ANN}

An ANN is a system that is based on operations of biological neural networks, and hence can be defined as an emulation of biological neural systems. ANN's are at the forefront of computational systems designed to produce, or at least mimic, intelligent behavior. Neural network systems have been developed for fields such as pattern recognition, capacity planning, business intelligence, robotics, or even for some form of intuitive problem solving. Data analytics is used in many industries to allow companies to either make better business decisions, or in science, to verify/disprove existing models or theories. Data analytics is distinguished from data mining by the scope, purpose, and focus of the analysis. Data Mining describes the process of discovering new patterns from large data sets, by applying a vast set of methods from

statistics, artificial intelligence, or database management. The main condition where this occurs is in the power transformer magnetization process, where the inrush current can reach high values causing the disconnection of the transformer [4]. During sudden jump of the terminal voltages the transformer magnetizing inrush currents may cause differential currents, which are several times greater than the rated level, and decay to that level within several seconds [6].

A. Power Transformer and Its Protection

Differential protection constitutes the main method of protection for large transformers and is highly recommended for transformers with power greater than 10MVA [4]. During the last years, several proposals of methods have been presented in order to solve the main difficulty that appears in the differential protection: the distinction between the magnetizing currents and internal faults [4].

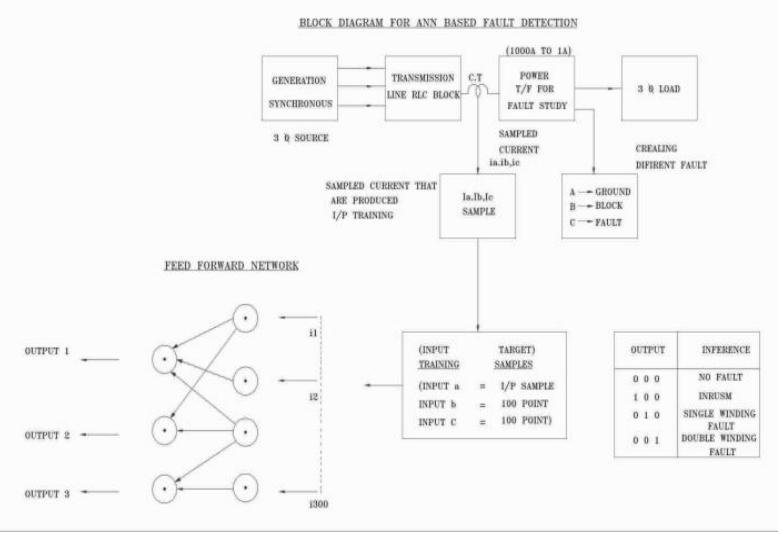

Fig 1.Block diagram for ANN based fault detection

Fig.1 shows block diagram for fault detection .The three phase power source includes synchronous generation, transmission line, power transformer, and load. The sampled currents ia,ib,ic are used in input training and 
INTERNATIONAL JOURNAL OF INNOVATIVE RESEARCH IN ELECTRICAL, ELECTRONICS, INSTRUMENTATION AND CONTROL ENGINEERING Vol. 3, Issue 12, December 2015

different faults (single,double,inrush)are detected using ANN.

B. Flowchart for Transformer Fault Identification Using ANN

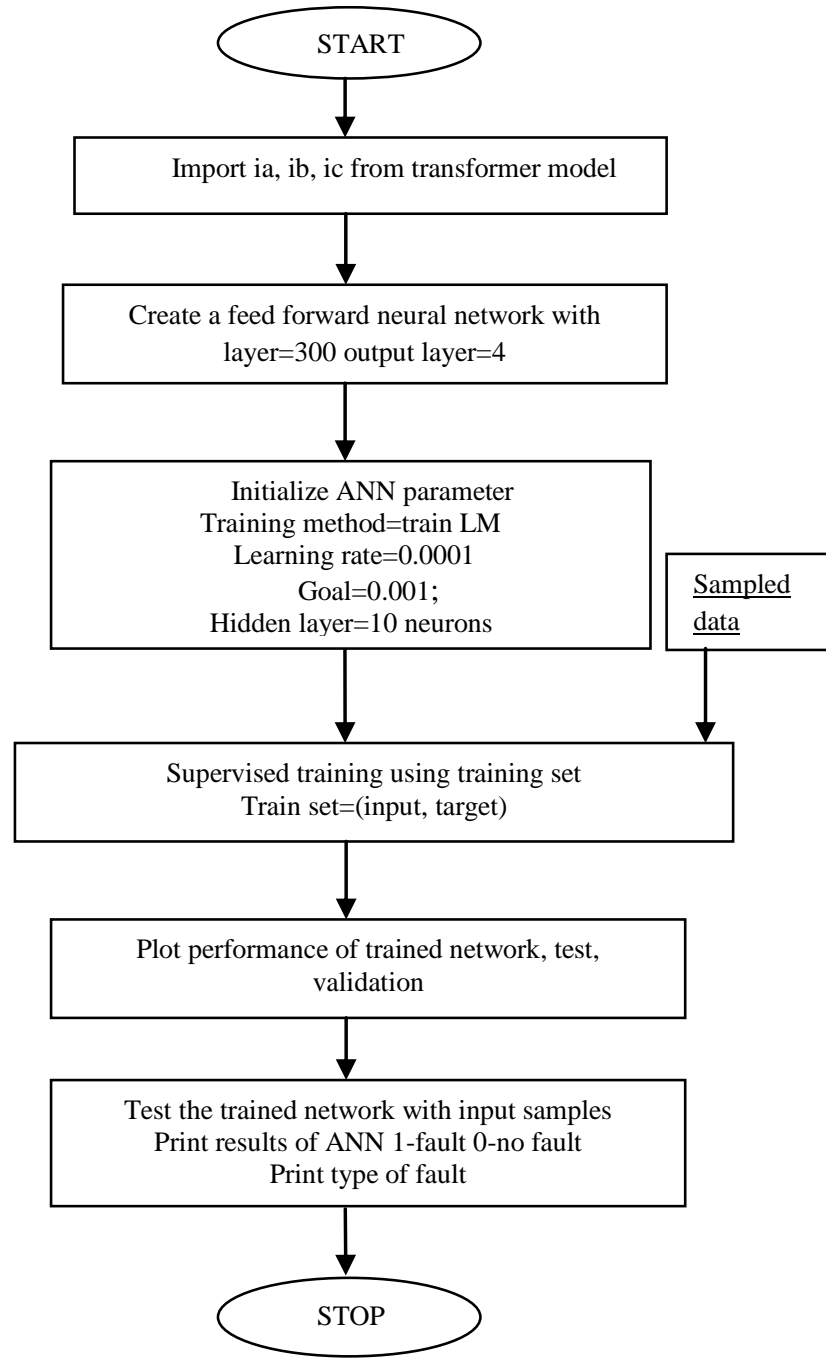

Fig.2. Flowchart for Transformer Fault Identification Using ANN

The transformer model creating a feed forward network with input and output layers. The trained network performances for plot, test and validation, and the results are given using ANN.

C. Proposed Algorithm for Fault Detection of Transformer Protection Using ANN

The various stages involved in the network development are data generation, feature extraction, and network training [3].The different kinds of faults are made to occur intentionally and data are collected at various conditions. The faults include turn to turn, winding to ground, and dielectric faults. The data are then processed and entered in the learning algorithms to recognize the type of fault [5].

The result of Levenberg-Marquardt algorithm was found to be faster than that of other algorithms. Therefore it is suitable for real time fault detection. Calculate net values, slopes, and outputs for all neurons in the first layer:

$$
\begin{aligned}
& \text { net }{ }_{j}^{l}=\sum_{i=1}^{n i} 1_{i} W_{j, i}^{1}+W_{j .0}^{1} \\
& \mathrm{Y}_{\mathrm{j}}^{1}=\mathrm{f}_{\mathrm{j}}^{1}\left(\text { net }{ }_{\mathrm{j}}^{1}\right) \\
& s_{j}^{1}=\frac{\partial f_{j}^{1}}{\partial \text { net }_{j}^{1}}
\end{aligned}
$$

Where

Ii are the network inputs the superscript " 1 " means the first layer $\mathrm{j}$ is the index of neurons in the first layer.

Use the outputs of the first layer neurons as the inputs of all neurons in the second layer, be a similar calculation for net values, slopes, and outputs:

$$
\begin{aligned}
& \text { net }{ }_{j}^{2}=\sum_{i=1}^{m} Y_{i}^{l} W_{j . i}^{2}+W_{j .0}^{2} \\
& Y_{j}^{2}=f_{j}^{2}\left(\text { net }{ }_{j}^{2}\right)
\end{aligned}
$$

Levenberg-Marquardt Training

$$
S_{j}^{2}=\frac{\partial f_{j}^{2}}{\partial n t_{j}^{2}}
$$

Use the outputs of the second layer neurons as the inputs of all neurons in the output layer (third layer), do a similar calculation for net values, slopes, and outputs:

$$
\begin{aligned}
& n e t_{j}^{3}=\sum_{i=1}^{n_{2}} Y_{i}^{2} W_{j, i}^{3}+W_{j, o}^{3} \\
& O_{j}=f_{j}^{3}\left(\text { net }_{j}^{3}\right) \\
& s_{j}^{3}=\frac{\partial f_{j}^{3}}{\partial n e t_{j}^{3}}
\end{aligned}
$$

After the forward calculation, node array $\mathbf{y}$ and slope array s can be obtained for all neurons with the given pattern. With the results from the forward computation, for a given output $\mathrm{j}$, the backward computation can be organized as Calculate error at the output $\mathrm{j}$ and initial $\delta$ as the slope of output j:

$$
\begin{aligned}
& e_{j}=d_{j}-O_{j} \\
& \delta_{i, j}^{3}=s_{j}^{3} \\
& \delta_{j, k}^{3}=0
\end{aligned}
$$

Where d $\mathrm{j}$ is the desired output at output $\mathrm{j}$ oj is the actual output at output $j$ obtained in the forward computation

$\delta_{i, j}^{3}$ is the self-back propagation

$\delta_{j, k}^{3} 3$ is the back propagation from other neurons in the same layer (output layer)

Back propagate $\delta$ from the inputs of the third layer to the outputs of the second layer

$$
\delta_{j, k}^{2}=W_{j, k}^{3} \delta_{j, j}^{3}
$$


where $\mathrm{k}$ is the index of neurons in the second layer, from 1 to $\mathrm{n} 2$.

Back propagate $\delta$ from the outputs of the second layer to the inputs of the second layer

$$
\delta_{j, k}^{2}=\delta_{j, k}^{2} s_{k}^{2}
$$

where $\mathrm{k}$ is the index of neurons in the second layer, from 1 to $\mathrm{n} 2$.

Back propagate $\delta$ from the inputs of the second layer to the outputs of the first layer

$$
\delta_{j, k}^{1}=\sum_{i=1}^{n_{2}} W_{j, i}^{2} \delta_{j, i}^{2}
$$

where $\mathrm{k}$ is the index of neurons in the first layer, from 1 to n1.

Back propagate $\delta$ from the outputs of the first layer to the inputs of the first layer

$$
\delta_{j, k}^{1}=\delta_{j, k}^{1} s_{k}^{1}
$$

where $\mathrm{k}$ is the index of neurons in the second layer, from 1 to $\mathrm{n} 1$.

The above algorithm is used to detect the fault, thereby it helps to clear the fault.

\section{III.RESULT AND DISSCUSSION TO DETECT FAULT FOR TRANSFORMER PROTECTION USING ANN}

A. Single Winding Fault for transformer

Problems with windings are mostly insulation degradation or breakdown. The degradation is caused by high temperature of the core or the conductor, and electric field applied to the insulation. The symptoms include the development of partial discharges and arcing. Overload and through fault cause excessive electrical overheating. Abnormal eddy current in the core causes excessive magnetic overheating. The overheating accelerates the degradation process. The Voltage and current transients due to single winding fault are simulated in MATLAB using SIMULINK models these are shown in Fig 3.This Transient information is processed through sampling and used for creating the sample set, which is further used for training the network. The training process for the neural network and fault diagnosis decision are implemented using toolboxes on MATLAB/Simulink.
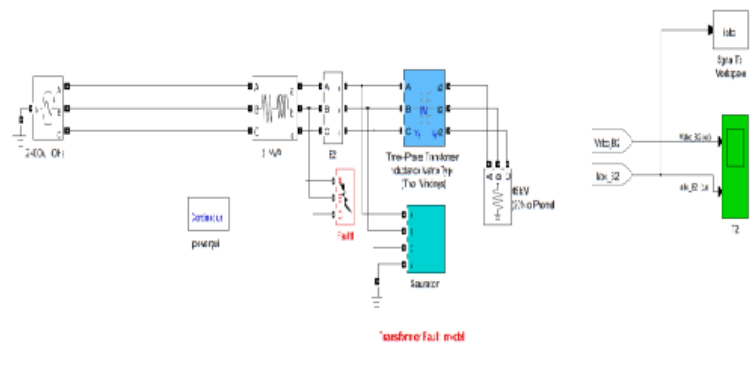

Fig.3.Simulink block diagram for single winding fault
Fig.5.shows shape of the validation plot and test plot are similar, this shows that the algorithms performance is smooth over the wide range of sample points. Waveform of current shown in Fig.4.

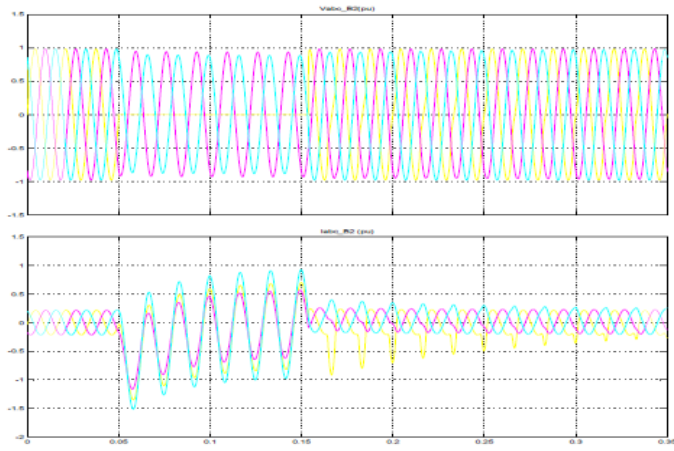

Fig.4.Waveforms of current

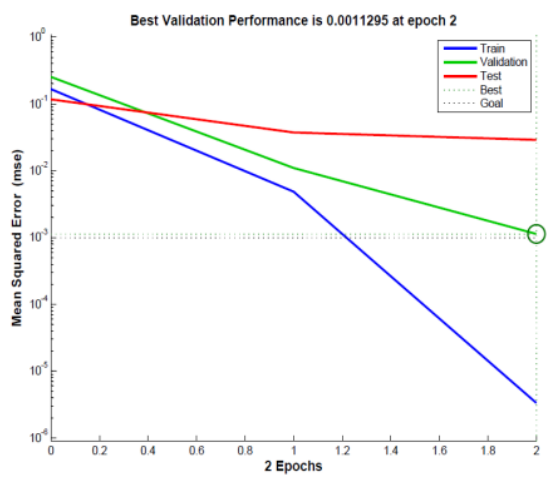

Fig.5.ANN Performance Plot for single winding fault

In single winding were the faults created at 0.05 and cleared at $0.15 \mathrm{sec} . \mathrm{x}$-axis represents time and $\mathrm{y}$-axis represents voltage and current.

B. Double Winding Fault for transformer

The Voltage and current transients during double winding fault are simulated in MATLAB using SIMULINK models; shown in Fig 6.This Transient information is processed through sampling and used for creating the sample set, which is further used for training the network. Waveform of current shown in Fig.7. The shape of the validation plot and test plot are similar this shows that the algorithms performance is smooth over the wide range of sample points shown in Fig.8.
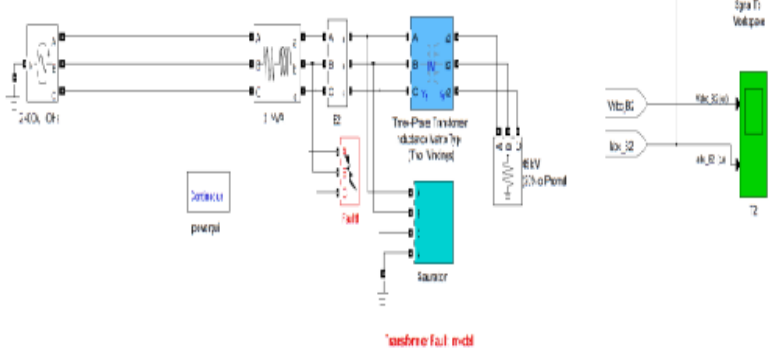

Fig.6.Simulink Block Diagram for Double Winding 

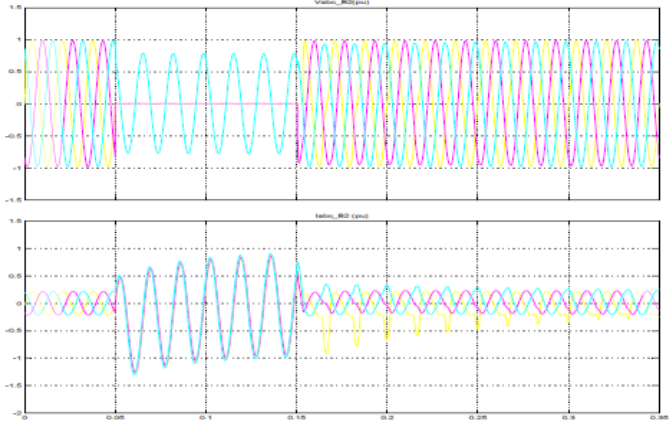

Fig.7.Waveform of Three Phase Voltage and Current Transient for Double Winding Fault

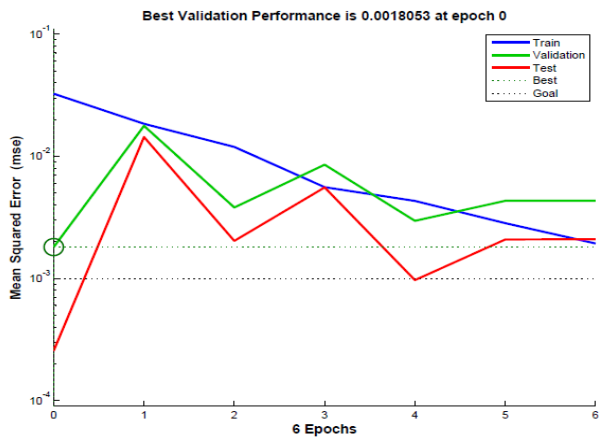

Fig.8.ANN Performances for Double Winding Fault

In double winding were the faults created at0.05 and cleared at $0.15 \mathrm{sec} . \mathrm{x}$-axis represents time and $\mathrm{y}$-axis represents voltage and current.

\section{For Inrush Current for transformer}

The Voltage and current transients due to Magnetic Inrush are simulated in MATLAB using SIMULINK models; these are shown in Fig.9.In this model a timed Circuit breaker is added, the same is closed at $\mathrm{T}=0.1$ seconds, this causes inrush currents in the transformer windings. waveform of current shown in Fig.10.This Transient information is processed through sampling and used for creating the sample set, which is further used for training the network.Fig.11.shows the training algorithm performance for the feed forward neural network structure. The shape of the validation plot and Test plot are similar this shows that the algorithms performance is smooth over the wide range of sample points. It is notable that the ANN network is able to discriminate the Inrush currents for fault currents this proves the reliability of the ANN network.

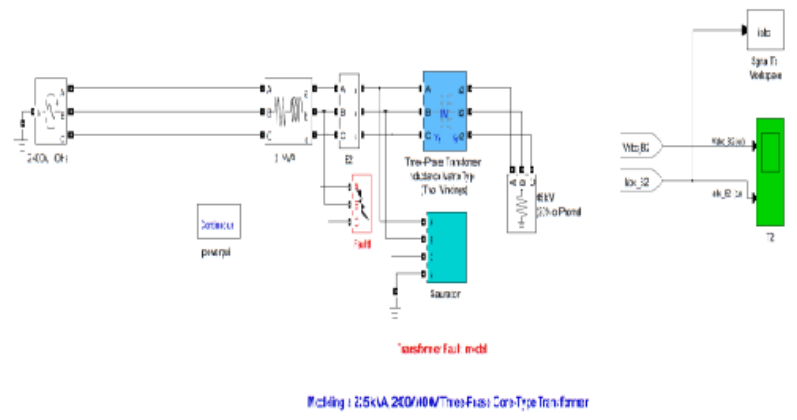

Fig.9. Simulink Block Diagram for Inrush Current

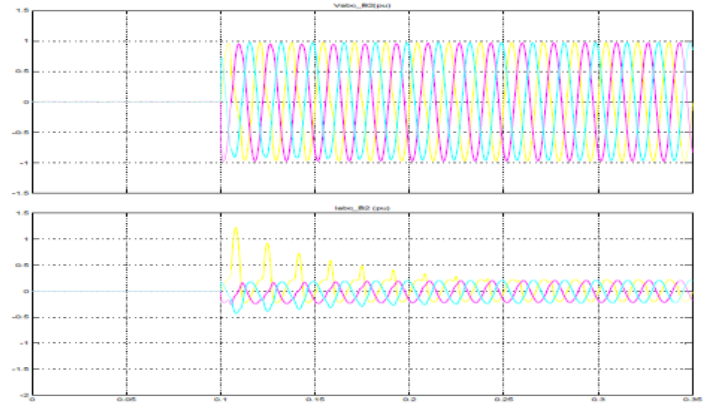

Fig.10. Wave form of magnetic inrush currents due to breaker

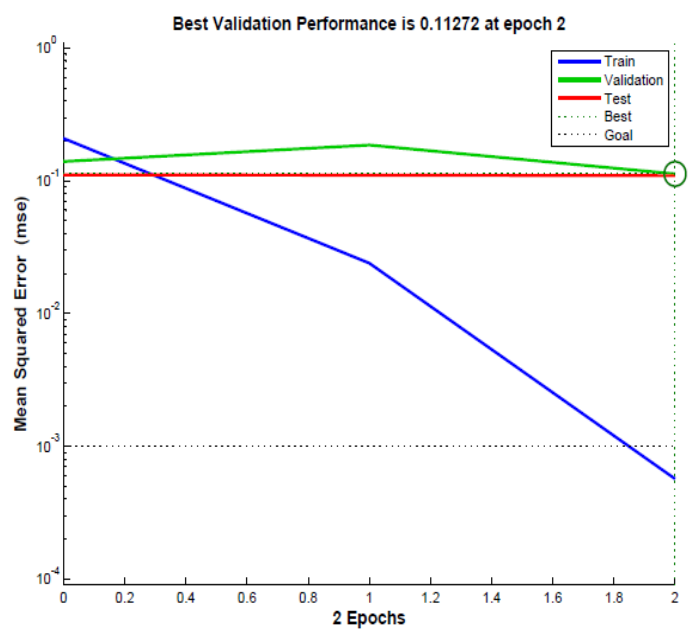

Fig.11.ANN performances for inrush currents

In inrush current were the faults created at 0.05 and cleared at $0.15 \mathrm{sec} . \mathrm{x}$-axis represents time and $\mathrm{y}$-axis represents voltage and current. Where blue line represents train, green line represents validation, red line represents test and dotted lines represents test and goal of the system.

\section{CONCLUSION}

The design details of the ANN-based fault diagnosis system for power transformer, especially for internal fault, have been presented. The evaluation of the performance of the proposed fault diagnosis system under various fault conditions leads to the following conclusions. The proposed architecture of the proposed fault diagnosis system has the advantage of assigning one task to each ANN. The adequate length of the data window is $1 / 2$ cycle samples of three phase voltages, primary and secondary currents. The response of the proposed fault diagnosis system is fairly fast due to its parallel structure. Therefore, the fault in single winding, double winding and inrush are created and cleared.

\section{REFERENCES}

[1] Harjit Singh Kainth and Gagandeep Sharma "A New Method for Differential Protection in Power Transformer", IOSR Journal of Electrical And Electronics Engineering, Vol. 9, Issue 2 ver. IV, pp.64-70, Mar - Apr. 2014.

[2] Suribabu.Miriyala, B. V. Sanker Ram and K. S. R. Anjaneyulu, "Protection of Power Transformer From Various Faults Using ANN", International Journal of Research in Engineering \& Technology ,Vol. 2, Issue 9, pp.13-20,Sep.2014. 
[3] Okan Ozgonenel and Serap Karagol, "A Novel Transformer Protection Method Based On Hilbert Huang Transform and Artificial Network" $8^{\text {th }}$ international IEEE conference proceeding of Electrical and Electronics Engineering (ELECO,) Bursa, pp.225228, Nov28-30.2013.

[4] N. Raidson Jenner, De Alencar and Ubiratan Holanda Bezerra, "Power Transformer Differential Protection Through Gradient of The Differential Current" International Journal of J Control Autom Electr Syst , pp. 62-173,Mar. 2013.

[5] A.M Saleh and M.Z Hossain, "A Learning System For Detecting Transformer Internal Faults" IEEE Conference Proceeding of Informatics, Electronics \&Vision (ICIEV), Dhaka, pp.1-6, May.17182013

[6] A.Wiszniewski, and W. Rebizant, "Sensitive Protection Of Power Transformers For Internal Inter-Turn Faults",IEEE Bucharest Power Tech Conference, Bucharest, Romania,pp 1-6 ,June2009.

\section{BIOGRAPHIES}

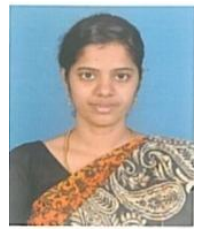

M. Priyadharshini was born on July 05 , 1985. She completed her B.E. degree in Electrical and Electronics Engineering in 2006, M.E. degree in Power Systems in 2013. She is presently Assistant Professor at Annamalai University, India. Her research interests include power system protection, transformer differential protection.

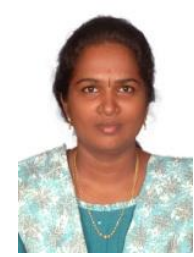

K. Gayathri was born on April 10, 1976. She completed her B.E. degree in Electrical and Electronics in 1999, M.E. degree in Power Systems in 2005 and also awarded her Ph.D in Electrical Engineering in September 2010 at Annamalai University. She is presently a Assistant Professor at Annamalai University, India. She has 20 publications to her credit. Her research interests include power system operation and control, power system analysis, fault diagnosis and artificial intelligence techniques to power systems.

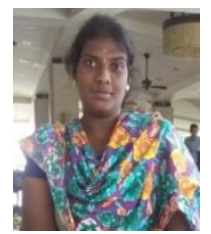

C. Poongothai was born on August 17, 1993. She completed her B.E. degree in Electrical and Electronics in 2014; she is pursuing her M.E Power Systems in Annamalai University, India. Her research interests include power system protection, fault diagnosis and artificial intelligence techniques to power systems. 